\title{
Rivaroxaban Causing Thrombocytopenia in a Case of Deep Vein Thrombosis (DVT)
}

\author{
Twinkle Pawar ${ }^{1}$, Yash Gupte², Sourav Chaturvedi ${ }^{3}$, Anusha Gupta ${ }^{4}$, Sourya Acharya ${ }^{5}$ \\ 1,2,3,4,5 Department of Medicine, Jawaharlal Nehru Medical College, Datta Meghe \\ Institute of Medical Science, Sawangi, Wardha, Maharashtra, India.
}

\section{INTRODUCTION}

Novel oral anticoagulants (NOACs) are used as alternative to intravenous anticoagulants. It includes apixaban, dabigatran, rivaroxaban and edoxaban. ${ }^{1}$ Some of the complications induced by these drugs are gastrointestinal haemorrhage, cerebral haemorrhage and rarely thrombocytopenia. We present a rare case report of a selective factor Xa inhibitor rivaroxaban, which induced thrombocytopenia in a case of deep vein thrombosis (DVT) of right lower limb. Drugs commonly used to prevent embolization of systemic circulation are warfarin and novel oral anticoagulants, such as rivaroxaban and dabigatran.

\section{PRESENTATION OF CASE}

A 34-year-old male patient presented to the casualty with the chief complaint of pain and swelling of right lower limb. He denied any history of hypertension, diabetes mellitus, trauma. The patient had no significant past history.

On general examination, patient was afebrile with a pulse of 84 per minute, blood pressure of $130 / 90 \mathrm{~mm}$ of mercury, and respiratory rate of $24 / \mathrm{min}$. On local examination, there was swelling on right lower limb with ecchymosis which was indurated and extending to medial malleolus. There were no signs of petechiae or bleeding tendencies. On neurological examination, the patient was conscious and oriented, heart sounds were normal, per abdominal examination was soft and nontender and chest on auscultation was bilateral clear.
Corresponding Author: Dr. Twinkle Pawar, Department of Medicine, Jawaharlal Nehru Medical College, Sawangi, Wardha, Maharashtra, India.

E-mail: pawartwinkle@gmail.com

DOI: $10.14260 / \mathrm{jemds} / 2021 / 548$

How to Cite This Article:

Pawar T, Gupte Y, Chaturvedi S, et al. Rivaroxaban causing thrombocytopenia in a case of deep vein thrombosis (DVT). J Evolution Med Dent Sci 2021;10(32):26872688, DOI: 10.14260/jemds/2021/548

Submission 27-01-2021,

Peer Review 10-06-2021,

Acceptance 16-06-2021,

Published 09-08-2021.

Copyright $(2021$ Twinkle Pawar et al. This is an open access article distributed under Creative Commons Attribution License [Attribution 4.0 International (CC BY 4.0)] 


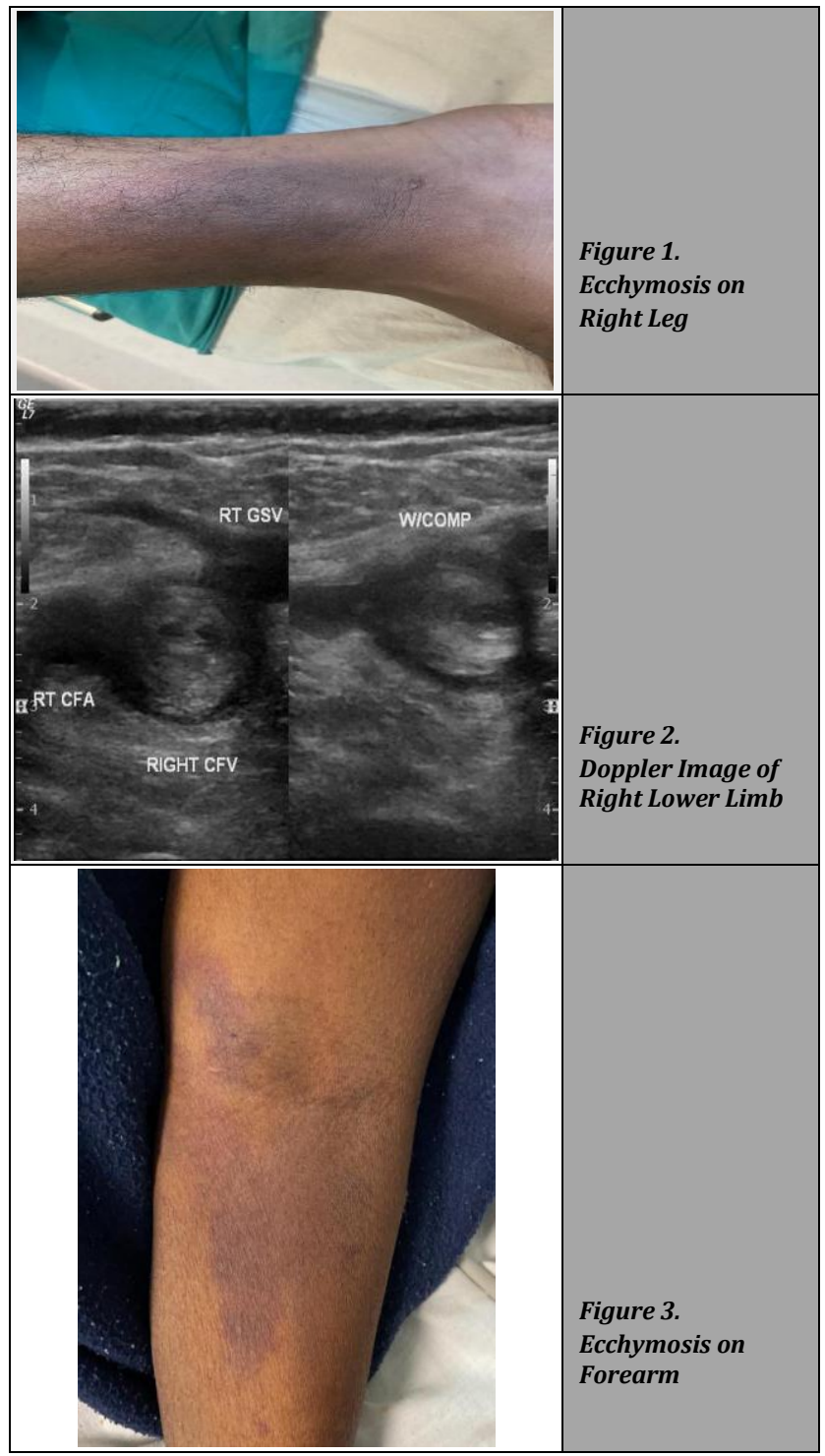

Doppler of the right lower limb was done which revealed deep vein thrombosis of right lower limb. Some general practitioner advised rivaroxaban as prophylaxis. He took the medications and presented to us in the out-patient department (OPD) after 3 weeks. Some laboratory investigations were advised which revealed $\mathrm{Hb}-11.4 \mathrm{gm} / \mathrm{dl}$, white blood counts $8,000 / \mathrm{mm} 3$, platelets $-18,000 / \mathrm{mm} 3$, with peripheral smear suggestive of predominantly normocytic moderately hypochromic with moderate anisopoikilocytosis with few pencil cells, C-reactive protein (CRP) 17.4, serum homocysteine 24.14, D-dimer 1.61, serum lactate dehydrogenase (LDH) 316, serum anti-nuclear antibody (ANA) was $0.80, \mathrm{HBsAg}$, hepatitis $\mathrm{C}$ virus (HCV) and human immunodeficiency virus (HIV) negative, reticulocyte count and coombs test being negative, kidney function test and liver function test were within normal limits. These investigations revealed thrombocytopenia. Then he was admitted. He was started on injectable ceftriaxone, injectable low molecular weight heparin and injectable dexamethasone.

On $2^{\text {nd }}$ day of admission, platelets were found to be $15,000 / \mathrm{mm} 3$. Then rivaroxaban was stopped. Prophylactically one-point platelet concentrate was given. Platelet counts were raised to $38,000 / \mathrm{mm} 3$. On $5^{\text {th }}$ day of admission, platelet count was raised to $2,00,000 / \mathrm{mm} 3$.

\section{DISCUSSION}

Drugs can directly reduce platelet formation in bone marrow or trigger an immune related process, which can increase platelet destruction. ${ }^{2,3}$ Because of its narrow therapeutic index when patients take warfarin, daily monitoring along with International standardized ratio (INR) and long-term patient education are required. ${ }^{2}$ The rivaroxaban-induced thrombocytopenia mechanism is not yet clear. No cell diseases were found in this case, except for thrombocytopenia. Moreover, once rivaroxaban was discontinued, the platelet count increased quickly. The study on platelet toxicity induced by factor Xa inhibitors is limited. Thrombocytopenia during the administration of NOACs may lead to severe haemorrhage considering that it occurs during anticoagulation therapy. When introducing an NOAC, measurement of the creatinine clearance and haemoglobin levels for the early detection of an occult haemorrhage is recommended. Changes in the platelet count must be carefully monitored while NOACs are being used in order to avoid haemorrhagic complications. ${ }^{4}$ Homocysteine levels were checked because homocysteine levels should be estimated and treated to prevent recurrent DVT and pulmonary embolisms. ${ }^{5}$ Blood test reports after starting rivaroxaban were also suggestive of thrombocytopenia, thus we could easily rule out heparin induced thrombocytopenia. We can confidently assert that the thrombocytopenia was caused by rivaroxaban.

\section{CONCLUSIONS}

High risk of life-threatening bleeding during anticoagulation therapy could be associated with this. Changes in platelet counts are to be carefully tracked at outset of NOAC care for elderly patients and we should be on lookout for bleeding incidents. Creatinine levels and haemoglobin must be assessed prior to use of NOAC.

Financial or other competing interests: None.

Disclosure forms provided by the authors are available with the full text of this article at jemds.com.

\section{REFERENCES}

[1] He XY, Bai Y. Acute thrombocytopenia after anticoagulation with rivaroxaban: a case report. World J Clin Cases 2020;8(5):928-31.

[2] Van Den Bemt PM, Meyboom RH, Egberts AC. Druginduced immune thrombocytopenia. Drug Saf 2004;27(15):1243-52.

[3] Carey PJ. Drug-induced myelosuppression: diagnosis and management. Drug Saf 2003;26(10):691-706.

[4] Mima Y, Sangatsuda Y, Yasaka M, et al. Acute thrombocytopenia after initiating anticoagulation with rivaroxaban. Intern Med 2014;53(21):2523-7.

[5] Dubey A, Acharya S, Gagneja S. Acute pulmonary embolism in a young male without deep vein thrombosis. Indian Journal of Medical Case Reports 2018(1):15-7. 